\title{
DEPORTE, OLIMPISMO Y JUVENTUD
}

Ivan Coste-Manière

Asociación Francófona de Academias Olímpicas ivan.costemaniere@skema.edu

Fecha de recepción: mayo 2018 Fecha de aceptación: octubre 2018

DOI: http://doi.org/10.15366/citius2018.11.2.003

Resumen:

El presente artículo corresponde a los resultados del debate, las reflexiones y las recomendaciones que fueron consecuencia del trabajo llevado a cabo por el Grupo Francófono número 1 que participó en las jornadas de la 14 Sesión International conjunta para Presidentes y Directores de Academias Olímpicas Nacionales y miembros de Comités Olímpicos Nacionales, celebrada en la Sede de la Academia Olímpica Internacional entre el 6-13 Mayo del 2018. Dicho grupo estuvo integrado por las once personas representantes de diferentes academias olímpicas y asociaciones internacionales de Academias Olímpicas; según se detalla en el apartado de la Introducción. Ha sido puesto como autor del texto que resume el contenido de aquel trabajo conjunto el señor Iván Coste-Manière, ya que es el autor del texto y su redacción, llevó a cabo el trabajo de recogida y escritura del contenido de las deliberaciones y se encargó de la exposición del resumen de las mismas ante la Asamblea General.

Palabras clave: Olimpismo, Valores Olímpicos, Movimiento Olímpico

\section{Title: SPORTS, OLIMPISM AND YOUTH}

\begin{abstract}
:
This paper focuses on the debate, reflections and recommendations which were the result of the work carried out by the Francophone Discussion Group number 1 in the 14th Joint International Session for Presidents or Directors of National Olympic Academies \& Officials of National Olympic Committees, held at the headquarters of the International Olympic Academy in Olympia (Greece) from May 6 to 13, in 2018. He has been cited as author of the text that summarizes the content of that joint work Mr. Iván Coste-Manière, since he is the author of the text and its writing, carried out the work of collecting and writing the content of the deliberations and was commissioned of the presentation of the summary thereof before the General Assembly.
\end{abstract}

Key words: Olympism, Olympic Values, Olympic Movement

\section{Introducción}

La 14 Sesion International conjunta para Presidentes y Directores de Academias Olímpicas Nacionales y miembros de Comités Olímpicos Nacionales, es una de las sesiones de trabajo que organiza anualmente la dirección de la Academia Olímpica Internacional (AOI) para debatir y poner en común el trabajo realizado por las Academias Olímpicas de los diferentes países y para plantear los retos que supone la actualidad para potenciar los valores que forman parte del Ideario Olímpico. Como consecuencia, entre el 6 y el 13 de mayo del 2018, Presidentes, Miembros de Academias Olímpicas y Técnicos de Comités Olímpicos de 92 países estuvieron reunidos en la sede de la AOI sita en Olimpia (Grecia). El tema y objetivo principal de la convocatoria fue debatir sobre «Deporte, Olimpismo y Juventud». 
Los miembros que integraron el Grupo de trabajo francófono $n^{\circ} 1$ fueron: Coordinadores: Profa. Dra. M. ${ }^{a}$ Eugenia Martínez Gorrono (Miembro de la Academia Olímpica de España), Jean Vintzel (Secretario General de la Asociación de Academias Olímpicas francófonas. Francia). Miembros: Sra. Nene Epouse Traore Toure, (Academia Olímpica Nacional de Mali), Sra. Maria Eduarda Vasconcelos (Presidenta de la AON de Cabo Verde), Sr. Dominique Paret (Miembro Tesorero de la AON de Francia), Sra. Maria Inés Sarubbi (Miembro de la AON de Paraguay), Sr. Gilbert Gresenguet (Presidente de la AON de la República Centroafricana), Sra. Alicia MBOLO (Jefa de Personal del Comité Olímpico de Camerún), Sr. Mohamed Moncef Temini (Director de la Asociación de Academias Olímpicas de África. AANOA), Sr. Iván Coste-Maniere (Vicepresidente de la Asociación Francófona de Academias Olímpicas. AFAO), Sr. Rocky Marciano (Presidente de la AON de Guinea Ecuatorial), Sr. Kayo Madjingar (Director de la AON de la República del Chad).

«No hay existencia sin pruebas, ni afecto sin abandono, no hay vínculo sin desgarro, no hay sociedad sin soledad, la vida es un campo de batalla donde los héroes mueren para que vivamos» (Boris Cyrulnik).

\section{Primer tema: Deporte, Olimpismo y juventud}

Los representantes de las Academias Olímpicas de Cabo Verde, de Mali y de la República Centroafricana se manifestaron de acuerdo en denunciar la brecha actual que observan entre la educación familiar y la educación olímpica. Por esa circunstancia, la representante de Malí informa que en su Academia Olímpica se ha emprendido la iniciativa de promover unos módulos dedicados a la capacitación de las mujeres para que, en su condición de madres, puedan mejorar el rol positivo que pueden ejercer las familias en la transmisión de valores.

Los programas de educación olímpica ${ }^{1}$ debían introducirse desde los primeros años en las escuelas, a fin de evitar el cambio social experimentado particularmente por la posición de aquellos padres que han pasado, de una posición previa en la que ponían el deporte en segundo lugar y en paralelo a los estudios, frente a verlo como una alternativa contemporánea liderándolo como señuelo de ganancia. El aprendizaje de los gestos de las diversas disciplinas del deporte por parte de los niños pequeños supone la provisión de materiales didácticos in situ, para profesores y formadores en general.

A nivel de base, convendría que se ampliase la oferta de las disciplinas deportivas que se ofrecen a los jóvenes para mostrar otras alternativas, y para diluir el riesgo de hacinamiento en las disciplinas exclusivamente lucrativas. ${ }^{2}$ Los valores educativos deben volver a colocarse en el corazón de las lecciones. La lucha contra la violencia, la delincuencia y el descontento se está convirtiendo en una preocupación omnipresente en cada uno de los países que están representados en este grupo de trabajo. Los valores contenidos en el Ideario Olímpico deben ser transmitidos junto con la práctica deportiva desde una edad muy temprana, y a partir de todos los formadores, ya sea en asociaciones de padres de alumnos, bien por parte de los maestros, los

\footnotetext{
${ }^{1}$ Se hace referencia con ello a las iniciativas de transmisión de los valores olímpicos y del ideario olímpico que llevan a cabo varias instituciones dentro de la estructura del Movimiento Olímpico, como las Escuelas Pierre de Coubertin, (puede verse por ejemplo el trabajo de Inés NIKOLAUS «Veinte años de la red internacional de escuelas Pierre de Coubertin», publicado en Citius, Altius, Fortius, Humanismo, Sociedad y Deporte: Investigaciones y ensayos, volumen 10, número 2, de noviembre de 2017. http://cdeporte.rediris.es/revcaf/CitiusAltiusFortius.html) y otras iniciativas de talleres, conferencias, intervenciones y participaciones en las escuelas, como por ejemplo la iniciativa del Comité Olímpico Español: «Todos olímpicos», jornadas que se llevan a cabo en los colegios de las Comunidades Autónomas de Madrid, Valencia, Extremadura y Canarias entre los escolares de 12 y 13 años o « Héroes olímpicos » iniciada en la Comunidad Valenciana entre los niños de tercer año de primaria que corresponde a la edad de 8 a 9 años.

${ }^{2}$ Se hizo referencia explícita e implícita a la tendencia tan frecuente que se produce entre la juventud de muchos países, influenciada por los medios de comunicación, en la que el futbol parece ser la única alternativa de práctica deportiva, que fomenta más las ambiciones de dinero y fama que puede potencialmente ofrecer que la visión de un deporte como forma de superación personal.
} 
entrenadores y otros profesores. La iniciativa de «la calle en el estadio» establecida por la República de África Central, así como las orquestadas por la Paz y el Deporte presididas por el Sr. Joel Bouzou y bajo el patrocinio de HSH Prince Albert II de Mónaco fueron resaltadas como encomiables a este respecto.

Con este propósito fueron señaladas varias iniciativas como la que se puso en marcha en Túnez, con un libro, «El Olímpico», que se introdujo como obligatorio para la educación primaria por el trabajo de influencia realizado por la Academia Olímpica y que fue adoptada como iniciativa de un exasesor especial del Presidente de la República.

Con el mismo propósito, la Real Academia Olímpica Española mantiene una iniciativa con la que ha conseguido crear 36 Centros de Estudios Olímpicos dentro de las estructuras de las universidades españolas, que se han creado a partir de la firma de convenios con los órganos de gobierno de las mismas. El objetivo de estos Centros de Estudios Olímpicos es difundir la filosofía olímpica y su ideario entre los docentes y los estudiantes de las comunidades universitarias. También se ha apoyado la introducción de los contenidos de los principios del Ideario Olímpico en los temarios de las oposiciones que deben superar los docentes.

En Cabo Verde, la existencia de 10 islas diferentes ha llevado al CON a crear antenas olímpicas, clubes olímpicos, etc., para difundir la filosofía olímpica.

Se citó a la Fundación Internacional Olympafrica como ejemplo, ya que sugiere aprender sobre deporte y valores, de forma que obligan a los jóvenes a un auto arbitraje, organizando equipos mixtos, buscando incluso la construcción de locales que ellos mismos gestionan y en los que ellos mismos participan.

El grupo desearía que la Academia Olímpica Internacional interviniese ante el COI para que se pueda desarrollar una estrategia y usar su peso político para que los medios de comunicación intenten revertir los impactos que originan, con una cobertura mejor y más justa de las llamadas disciplinas menores o sobre el deporte paralímpico, que ayudaría también a ralentizar algunos incrementos salariales. No todos los países tienen la «posibilidad» como España o Japón de tener un solo interlocutor. ¿Cómo hacer coincidir los «esfuerzos educativos» de los diversos jugadores de los movimientos olímpicos, paralímpico y deportivo y alinearlos con los de los encargados o ministerios interesados?

Hacer coincidir ideal y deporte es sin duda el punto crucial, evitando la dilución de las energías y las interferencias.

Con respecto a los otros temas propuestos: «Coherencia entre el modelo, la moda y la forma de vida», (¿Cómo evitar que un modelo se convierta en un Dios?) «La educación y el deporte de élite», el Grupo decidió fusionarlos y tratarlos de manera conjunta en un segundo tema: Educación olímpica y Deporte de élite: Ejemplaridad, explotación y limitaciones del modelo.

\section{Educación olímpica y deporte de élite}

Sería de gran interés la introducción sistemática de cartas éticas muy restrictivas y con capacidades legales leoninas, a partir del modelo de la Carta Olímpica, por parte de las Federaciones en todos los niveles, para obligar a los deportistas y atletas a respetar un comportamiento correcto, digno de los valores que ellos deben representar, teniendo en cuenta la influencia que ejerce su imagen en su área geográfica; puesto que en gran número de ocasiones el modelo que ofrecen los deportistas no coincide con un modelo que debe ser el de un líder social. Aquí, nuevamente, se debe tener en cuenta el papel definitivo que desempeñan los medios de comunicación, pues con mucha frecuencia difunden aspectos que podemos calificar de «contra-valores». Fueron mencionadas en este sentido el modelo de las conferencias 
de Monaco Sportel, con temas centrados en torno a estos problemas. Algo similar podría muy bien ser organizado por las Academias Olímpicas Nacionales, orientando, por ejemplo, a la toma de conciencia entre los jóvenes estudiantes de las escuelas de periodismo. De la misma manera, y para contribuir positivamente en este sentido, la Academia Olímpica Internacional podría organizar jornadas para la capacitación de los periodistas.

Lo importante siempre es que el nivel de conciencia de los practicantes debe ser potenciado siempre y con la mayor frecuencia posible.

La disciplina, en ausencia de la autodisciplina, tanto en el deportista de élite, como en los deportistas de nivel medio e incluso en los deportistas no profesionales, debe ser el centro de los esfuerzos que lleven a una aplicación de sanción. Esto presupone que los diversos reglamentos y estatutos legales promulgados por la ley local, como los estatutos y los reglamentos federales, deben de tener una total coherencia, y establezcan severas sanciones exigibles y pagaderas sólo por el deportista que infrinja la normativa y cometa la sanción, y no por sus patrocinadores.

«El mejor maestro solo puede enseñar siempre es el niño el que realiza el asombroso acto de aprender» (Fernando Savater, 1947).

\section{Bibliografía}

- Binder, D. (2007). Teaching values: an olympic education toolkit. A Project of the International Olympic Committe. Laussanne Switzerland.

- Calle Molina, M. y Martínez Gorroño, M. E. (2014). Presencia o ausencia de los valores del Movimiento Olímpico en el currículo español de Educación Secundaria Obligatoria en educación física: Un estudio de dos casos. Citius, Altius, Fortius. Humanismo, sociedad y Deporte: Investigaciones y ensayos, 7(1), 99-121. Centro de Estudios Olímpicos de la Universidad Autónoma de Madrid. Recuperado de http://cdeporte.rediris.es/revcaf/Numeros\%20de\%20revista/Vol\%207\%20n1/Vol7 $\underline{\text { n1_Calle_Martinez.pdf }}$

- Coubertin, P. (2012). La educación inglesa. En Citius, Altius, Fortius: Humanismo, Sociedad y Deporte: Investigaciones y ensayos, 5(1), 133-151. Madrid: Centro de Estudios Olímpicos de la Universidad Autónoma de Madrid y Comité Olímpico Español.

- Durántez Corral, C. (s/f. a). El movimiento Olímpico moderno y su filosofía: El ideario. España: Academia Olímpica Española.

- Durántez Corral, C. (s/f. b). Academias Olímpicas Nacionales. España: Academia Olímpica Española.

- Durántez, C. et. Al. (2008). Everybody's Olympic medal: Olympism and Sport values and symbols. Comité Olímpico Español. Madrid. España.

- Olympic Charter (2015). International Olympic Committee. Lausanne (Switzerland). 